\title{
Dynamics of Soil Salinity in Irrigation Areas in South Kazakhstan
}

\author{
Shakhislam Uzakbaevich Laiskhanov ${ }^{1,2 *}$, Azimbay Otarov ${ }^{2}$, Igor Yuryevich Savin ${ }^{3}$, \\ Samat Isembayevich Tanirbergenov ${ }^{2,4}$, Zheken Umbetkulovich Mamutov ${ }^{1}$, \\ Saken Nurzhanuly Duisekov ${ }^{2,4}$, Arseniy Zhogolev ${ }^{3}$
}

\author{
${ }^{1}$ Al-Farabi Kazakh National University, Almaty, Kazakhstan \\ ${ }^{2}$ U.U. Uspanov Kazakh Research Institute of Soil Science and Agrochemistry, Almaty, Kazakhstan \\ ${ }^{3}$ V.V. Dokuchaev Soil Science Institute, Moscow, Russian Federation \\ ${ }^{4}$ Kazakh National Agrarian University, Almaty, Kazakhstan
}

Received: 5 January 2016

Accepted: 30 January 2016

\begin{abstract}
The analysis has been conducted of possibility of determining the extent of soil salinity by indirect and direct decoding of satellite images Pleiades 1A / 1B (in the year of survey) and LANDSATTM (archive). It was found that indirect decoding of salinity based on spectral char-acteristics of vegetation images is strongly dependent on crop growth phase (period of shoot-ing). LANDSAT archive images with normalized soil salinity index (NDSI) allow to develop salinity maps and soil salinity dynamics maps at semi-quantitative level. Based on computer analysis of LANDSAT images it was determined that soil salinity at study object during the pe-riod from 1987 to 2014 has increased due to significant decrease of the area of non-saline soil by $41.5 \%$ and increasing of the areas of low and moderately saline soils by $34.9 \%$, also regions with heavily saline soils at $6.6 \%$ of total surveyed area have been detected, which previously were absent.
\end{abstract}

Keywords: regression analysis, soil salinity, geostatistical methods, information system, soil salinity dynamics map

\section{Introduction}

As a natural system, each terrain has important properties: self-organization, self-regulation, and selfrenewal - all of which facilitate sustainable development of an ecosystem and its ability to resist degradation and crisis processes. Sustainability of terrain is associated with the ability of its components to conserve their structure and function under external influences [1].

*e-mail: shah 394@mail.ru
At present, the impact of anthropogenic factors often exceeds maximal permissible limits, destroying natural ecosystems. First of all, land degradation results in expanded water and wind erosion, reduction of groundwater level, pollution, water logging and salinity of irrigated and non-irrigated soils [2]. Especially in arid regions where productivity of agricultural production is dependent on land irrigation, and soils are mostly subjected to salinity. The following six groups of degradation have been outlined in the World Atlas of Desertification [3]: water erosion, wind erosion, soil fertility decreases, salinization, 
waterlogging, and lowering of the groundwater level. Among them, salinization has been explored as the most relevant issue for Central Asia [4-5] and Kazakhstan [6-7].

Currently in the Republic of Kazakhstan, saline and alkaline soils occupy 111.6 million ha., or $41.0 \%$ of the nation [4]. The share of salt marshes in soil surface structure is significantly increasing in the southern part of the country, which represents a closed inland area that does not have free effluent to ocean basins. Extensive use of fertility of irrigated soils during the transition period (after the collapse of the Soviet Union, in particular), the poor state of irrigation and drainage networks, and non-compliance of their technical parameters with project standards have resulted in sharp deterioration of soil-reclamation conditions of irrigated areas. Here, 42,912 hectares of soil have unsatisfactory reclamation status due to salinity, 80,005 ha due to the rise of groundwater level, and 24,909 ha due to both factors [5]. Lack of a permanent operational monitoring system of irrigated soils has also contributed to this fact. Currently, traditional methods of exploring salinization dynamics by means of major salt surveying and soil salinity mapping are not used, mainly due to high costs. Therefore, currently one of the main problems in the Republic is that there is no reliable and timely data on soil-reclamation status of irrigated areas, as well as data on the development of secondary soil salinization and its impact on crop yields.

In this regard, currently there is an urgent need for the development of satellite techniques for soil salinity monitoring, which is considered one of the relevant new directions in research on dynamics of changes in saline soils. These methods are fundamentally different from their analogue land surface mode of exploring soil-salt regimes, and it is more operative, accurate, and comparatively cheaper. A review of recent scientific publications shows that the issue of analyzing saline soil dynamics in large areas has not been addressed [8-12]. A large number of publications has been devoted to the possibility of exploring soil salinity based on decoding satellite data, which is regarded as one of the main sources of information for the analysis of soil salinity dynamics [13-17]. Currently most researchers use Landsat TM and ETM + satellite data and can also use Landsat MSS data [18-21] for monitoring. Several researchers use Ikonos IRS-II LISS-II and III data. Works also use ASTER and MODIS data [22-25]. An overview of scientific publications shows that currently there is no global unified methodology for space monitoring of soil salinity, and all works in Kazakhstan still have an exploratory character. In this regard, the main objective of this work is to develop a method of determining soil salinity dynamics based on satellite data.

\section{Research Area}

The research object includes soil patterns of the Shilik and Aktobe rural districts in the Shaulder irrigation area in the Otyrar District of southern Kazakhstan (Fig. 1). The figure shows that from east and south, the area is framed by a gently sloping plain of ridges of the West Tien Shan and Karatau. The Kyzyl Kum sandy area serves as a natural boundary in the west, and in the north and northwest it borders with the Turkestan irrigation area. Most of the area is used as pasture for grazing farm animals, and the southern and eastern parts along the valleys of the rivers Shayan and Bugun are plowed as irrigated arable land. Terrain of the area is represented by slightly wavy or horizontal surface with poor and monotonous flora. Here dominate various species of wormwood (Artemisia), salt plants (Salsola), and jantak (Alhagipseudalhagi). The river valleys are rich in meadow grasses, thickets of wild rose (Rosa), and groves of poplar (Populus) and elm (Ulmusfoliacea). Saline ajrek (Aeluropuslittoralis) are near floodplains [26].

The climate is sharply continental and desert. Temperature in the winter falls to $-25^{\circ} \mathrm{C}$. The Syrdarya River usually freezes in early December and ice stays until March. Often in spring the Syrdarya and Aris overflow their banks, flooding a large area [27].

The leading crops in these rural districts are fodder crops: corn for grain, alfalfa, and rarely cereals, vegetables, and melons. The Bugun River is the main source for irrigation water, and on this river the reservoir with the same name is constructed. The water supply network is represented by different open-type sprinklers that are laid in natural ground and, of course, serve as an additional source of groundwater supply.

The area is dominated by meadow-gray soil saline (Solonchak, sometimes saline) soils (Xerosols) occupying mid-level surfaces that are formed on saline weakly layer loamy and clay sediments in medium depth (4-6 m) saline groundwater under the sparse grasshalophytic shrubs with ephemerals and wormwood

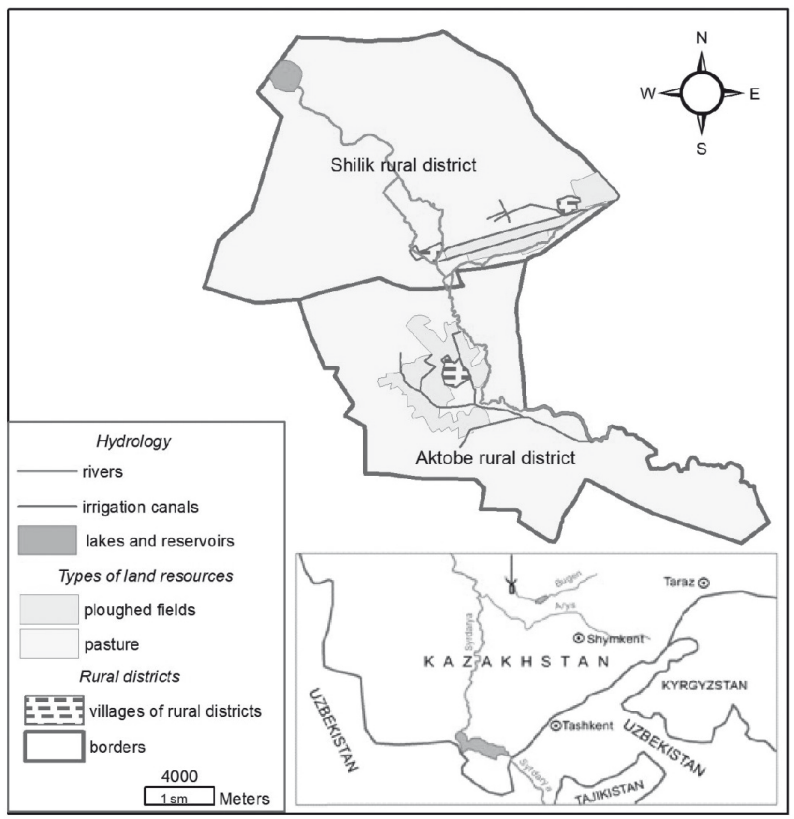

Fig. 1. Research area. 
(Artemisia). Also here are meadow-gray SolonetzGeyic soils, occupying average level surfaces and micro-terrain depressions, under-halophytic wormwood, wormwoodhalophytic, and halophytic vegetation with ephemeral plants, as well as Solonchaks-Gleyic, located on microterrain rises to 20-30 (50) $\mathrm{cm}$ of relative height under sparse halophyte plants - mostly leafless barnyardgrass (Echinochloa).

Solonchaks and Solonetzs are formed here, as a rule, on heavier and saline deposits under conditions of high mineralization of average-depth groundwater. In terrain depressions with close (up to $3 \mathrm{~m}$ ) groundwater, the following soils are formed: meadow-swamp saline soils under meadow-marsh vegetation at very close $(1.5 \mathrm{~m})$ slightly mineralized waters, gray-meadow saline salt marshes under halophytic and grass-halophytic vegetation on close slightly mineralized waters, meadow marshes under halophytic grass-halophytic vegetation at close (1.5-3 m) slightly mineralized waters, and ordinary salt marshes under halophytic vegetation at close heavy mineralized groundwater.

Salt marshes laying in complexes and combinations usually occur at elevated areas of micro- and mesoterrain [28] relative to other soils. The prevailing salinity type is chloride-sulphate and sulphate-chloride, sometimes with the presence of normal soda. All soils of the area are carbonate and are characterized by high alkalinity (pH 8-9). Water-physical, physical, and physical-chemical properties of soils depend on the degree of salinization and alkalinization.

According to conditions of groundwater supply and outflow, the area refers to hydro-geological region of intense external inflow and hindered outflow of groundwater and due to this fact, soils in this area are subject to secondary salinization. Former farm canals, collectors, and vertical drainage wells have been neglected, and their parameters do not meet the project standards and also result in raising the groundwater level and thus result in secondary salinization. We also know that in terms of irrigation, soil formation processes are sufficiently intense and have a relatively high rate of mobilization and migration processes. Therefore, monitoring fertility levels, especially salinization of irrigated soils, must be carried out regularly and include a wider range of soil properties to be determined.

\section{Materials and Methods}

Our work was carried out by means of space and ground soil surveys of the research area that were synchronous in time and location. For this purpose, by means of conducting ground reconnaissance survey of the area, were have chosen subsatellite areas with contrasting soil salinization, and satellite images have been ordered from Pleiades $1 \mathrm{~A} / 1 \mathrm{~B}$ in panchromatic mode with spatial resolution of $0.5 \mathrm{~m}$ on the site, and in multispectral mode (4-channel mode) with spatial time-resolution about $2.0 \mathrm{~m}$ on the site. In addition, LANDSAT satellite data collection for previous years was done from open sources (USGS) aimed at exploring the long-term dynamics of soil salinization.

Corn for grain and alfalfa are the major crops on the research object, as well as in the whole Shaulder irrigation area. Based on biological features of these crops and the length of their vegetation period data at the Institute of Soil Science, the last week of July was selected as the period for space and ground surveys. It was assumed that at this time corn will be in the buttonhole phase, and alfalfa at the beginning of the flowering phase (second mowing), i.e., at this time it is possible to measure vegetation index using ground and space-based techniques.

In regard to satellite data processing methods and decoding of soil salinity state, we can outline the following main approaches:

- Calculating vegetation indexes that facilitate identification of soil salinity.

- Using statistical models and methods (multiple regression, method of principal components, maximum probability method, regression of partial least squares).

- Using geostatistical techniques (kriging, co-kriging, modified kriging).

A review of literature revealed that such methods as partial least squares regression (among regression methods), principal component analysis, co-kriging, and modified kriging provide reliable results and high accuracy. It should be noted that when using the regression approach, it is also recommended to use the probability ratio test, the Lagrange multiplier, and corrected information criterion Akaike [29-32]. Note that decoding saline soils can be done using the character of exposed soil surface as well as by analyzing vegetation. In the latter case, the applied methods of decoding may be the same, but during decoding of soil salinity based on the status of vegetation, it is necessary to include the unit of identification of crop types cultivated in a particular growing season into the satellite monitoring system. In addition, we should pay attention to the fact that hyperspectral and radar satellite data can also be used for researching saline soils [33]. However, methods for their use are insufficiently developed.

Regression analysis of the correlation between magnitude of electrical conductivity measured in the field, and space images, was used for decoding satellite images. It was performed in the program Statistica v10.0 media for each soil layer $(0-20 \mathrm{~cm}, 20-50 \mathrm{~cm}, 50-100 \mathrm{~cm})$ and separately for alfalfa and corn. The sampling for cornfields was 25 points, and 30 points for fields with alfalfa. The folowing predictors were used for regression analysis:

1. Spectral channels of satellite Pleiades 1A/1B:

a) Blue (Channel1), Green (Channel 2), Red (Channel 3), and Near Infrared (Channel 4).

2. Correlation channels of Pleiades $1 \mathrm{~A} / 1 \mathrm{~B}$ :

a) $\mathrm{B} / \mathrm{G}=$ Channel $1 /$ Channel2, $\mathrm{R} / \mathrm{G}=$ Channel $3 /$ Channel 2, B/ NIR = Channel1 / Channel 4, B / $\mathrm{R}=$ Channel1 / Channel 3, NIR / G = Channel4 / Channel 2.

3. Vegetation index, describing the state of vegetation [34]: 
a) $\mathrm{NDVI}=$ (Channel4-Channel3) $/($ Channel4Channel3), IR_R = Channel4-Channel3, SQRT= $\mathrm{J}($ Channel4-Channel3).

b) $\mathrm{VEGI}=$ Channel4-Channel3, TND $\mathrm{VII}=\mathrm{J}$ ((Channel4-Channel3)/(Channel4-Channel3) $)+0.5$.

c) GNDVI=(Channel4-Channel2 $) /($ Channel4Channel2 $), \mathrm{NDGR}=($ Channel2 - Channel3 $) /$ (Channel2-Channel3).

Ground-based research was conducted according to the "All-union instructions ..." and "Guide on conducting ..." [35-36]. In addition, during the fieldwork we used the latest equipment for the study of soil salinity and global positioning systems. For conducting salt shooting, along with the traditional method (layer survey, well drilling) we also used field portable Progress 1T salt-meters [37]. To clarify the shapes of saline soils based on satellite imagery we used a Garmin GPS 18 paired with an ASUS netbook, and to determine layer point coordinates we used a Garmin 62 GPS unit.

\section{Results and Discussion}

Our work began with the creation of the basic GIS layers within the Shilik and Aktobe rural districts (research objects), including borders of irrigated sites, settlements, roads, lakes, rivers, irrigation network, etc. All the layers that make up the GIS were obtained by decoding Pleiades space imagery for 2014, and also land use maps of local farmers. After conducting fieldwork, field observation points and results of satellite imagery of the research object were added into GIS.

Also, we conducted an analysis of availability of archived satellite data on the research territory. It was established that from 1985 to 2014 in the archive there is a sufficient number (46) of LANDSAT images of high spatial resolution. These images were later used as the basis for identifying soil salinity dynamics in the research region.

As a result of regression analysis for the Pleiades satellite image $1 \mathrm{~A} / 1 \mathrm{~B}$ of 15 July 2014, the statistically significant regression with determination coefficient $\left(\mathrm{R}^{2}\right)$ of 0.51 was determined only for soil salinity in the $20-50 \mathrm{~cm}$ layer for plots with corn.

The above-determined pattern to some extent can be explained by the fact that in the Shaulder irrigation area, irrigation of corn begins in the phase of 7-8 leaves at the end of June and finishes in the second half of August. During this time, 4-5 irrigations with a norm of $600-700 \mathrm{~m}^{3} /$ ha were undertaken. These irrigations promote desalination of upper topsoil that can strongly reduce linkage between soil salinity and spectral properties of satellite imagery.

Multiple regressions have also been developed for Landsat satellite imagery for day 284 in October 2014, but they also have very low values of determination coefficients $\left(\mathrm{R}^{2}\right)$ of about 0.3 . The only significant regression was built for one $50-100 \mathrm{~cm}$ layer of soil under corn. The best predictors were 5 and 4 channels of the image.

As it was not possible to build sufficiently reliable re- gression models using the images for mapping salinity, we used a different approach using image classification and determination of salinity index NDSI. Since in most cases fields in the research area are abandoned due to high soil salinity, first of all masks of abandoned fields were built. For this purpose a pair of Landsat satellite images acquired during recent years have been used to exclude temporarily unused fields. In the images of 2013 and 2014 for days 280-285 (October), the abandoned fields have been automatically decoded using ILWIS 3.3.1, with the help of supervised classification on training sampling by the "greatest similarity" method. Classification was carried out in a combination of channels (4-3-2). The imagery acquired in 1988 shows that all agricultural plots were used. Thus the abandoned fields have outlined which soils were considered the most saline.

Less saline soils have been decoded based Landsat 5TM on satellite images during the second half of autumn, when images show the open soil surface: day 312 in 1988 (October) and day 332 in 2014 (November). Normalized index of salinity (NDSI) was calculated for each image. A variation of the indexes of channels 5 and 4 of satellite Landsat was used, as these channels are the most frequent as significant predictors in construction of salinity regression models: NDSI $=($ Channel5 - Channel 4$) /$ (Channel5 - Channel 4), in which Channel4, Channel5 respective channels of Landsat satellite.

Then the image of NDSI indices were divided into three classes corresponding to non-saline, slightly saline, and medium-saline soils. Quantile counted on imagery for day 332 in 2014 were used as class boundaries. Quantile values are $p(0.33)=0.26$ and $p(0.66)=0.28$. Furthermore,

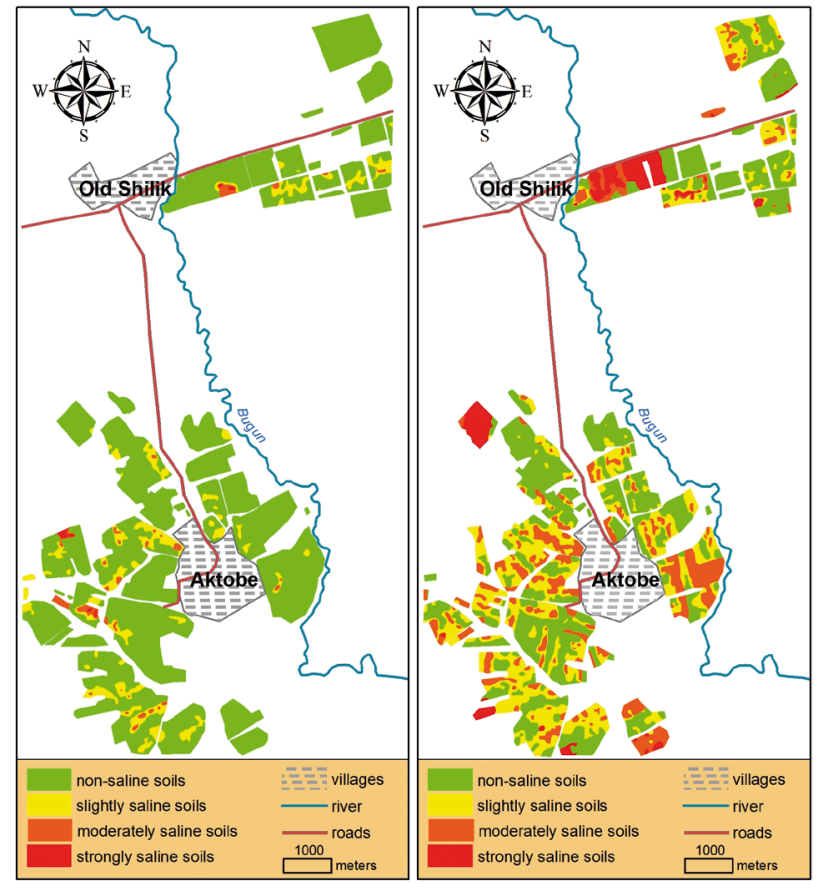

Fig. 2. Salinity maps (left - in 1988, right - 2014, Signs: 1 - nonsaline, 2 - slightly saline, 3 - moderately, 4 - strongly saline) as a result of LANDSAT images decoding. 


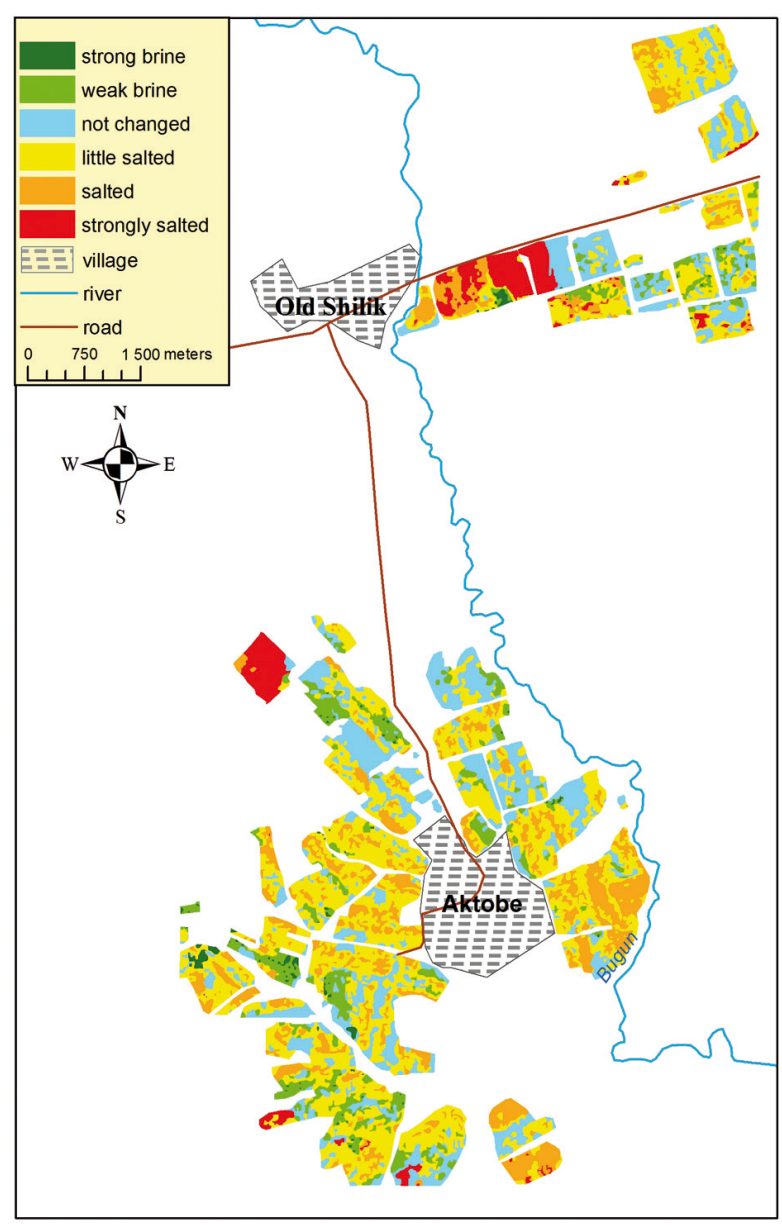

Fig. 3. Map of soil salinization the dynamics of research object for the 1988-2014.

we combined masks of heavily saline soils (unused fields) and non-saline masks, slightly saline, and medium-saline soils final salinity maps for 1988 and 2014 (Fig. 2).

Also, a map of salinity dynamics was built to assess the dynamics of salinity (Fig. 3). The rate of salinity change was marked in green for desalination process; gray for unchanged salinity; and yellow, orange, or red for increased levels of salinity. So, on the map the most

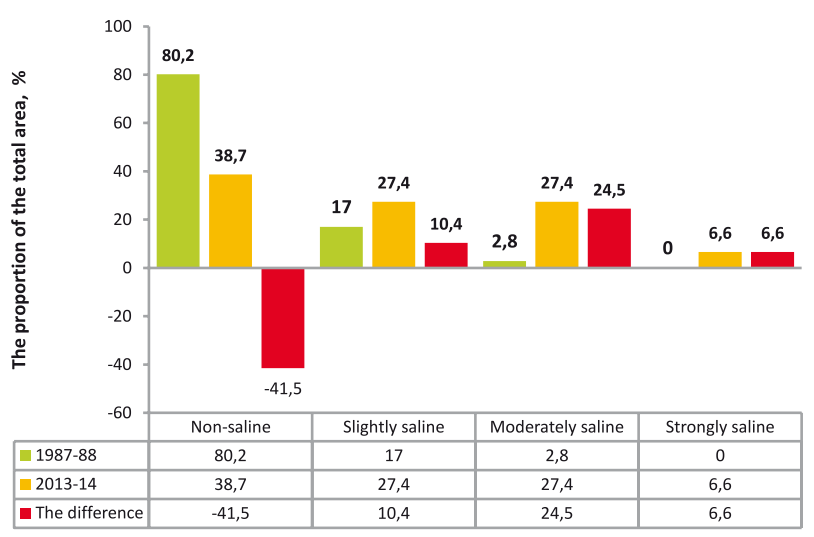

Fig. 4. The dynamics of soil salinization in the period from 1987 to 2014 . contrast comes from the images of soils where salinity has significantly increased or decreased.

Based on the map of soil salinity dynamics of research object (2262.9 ha), soil contour areas with varying degrees of salinity for 1987-88 and 2013-14 were calculated in GIS media, and the degree of change was determined (Fig. 4). As shown in Figure 4, for the past 26 years nonsaline soil areas have significantly changed, reducing the area by $41.5 \%$ or 939.4 ha.

Due to reduction of the area of non-saline soils, the areas of medium and strongly saline soils have increased, respectively, by 10.4 and $224.5 \%$ or 235.3 and 555.2 hectares. There appeared contours of strongly saline soils, which occupy $6.6 \%$ of the surveyed area. That is a result of studying the dynamics of soil salinity using satellite images, and it has been determined that over the last 26 years in Shilik and Aktobe rural districts progressive salinization is taking place. Highly saline soils cover mainly the peripheral parts of the area, and the end portions of the main irrigation canals, and contours of moderate soils are found everywhere.

\section{Conclusion}

Using regression analysis of linkage between spectral properties of Pleiades space image 1A/1B and LANDSAT archival images and electrical conductivity of irrigated soils, it became possible to build salinization regression models only for particular soil layers under corn, and they are not reliable enough statistically, apparently due to the inappropriate choice of the image period.

Probably indirect decoding of salinity on spectral characteristics of vegetation images would enable us to get more qualitative regression models. In this case, we should take into account crop vegetation phases when selecting images.

Salinity maps and a map of salinity dynamics were built on a semi-quantitative level using automated image classification on learning selection using "maximum similarity" and dividing soil imagery based on NDSI salinity index values. Strongly saline soils were identified most accurately, while soils with other salinity degrees were outlined with less precision. However, analysis conducted using LANDSAT archive images showed that soil salinity in the research object for the period from 1987 to 2014 has increased significantly. This was due to a significant decrease in the area of non-saline soils and an increase in the area of low and moderately saline soils. Also, previously absent contours of strongly saline soils have appeared.

\section{Acknowledgements}

The authors thank to the V.V. Dokuchaev Soil Science Institute and U.U. Uspanov Kazakh Research Institute of Soil Science and Agrochemistry, where this research was conducted. 


\section{References}

1. KARGIN V.I. Degradation, protection and regeneration of natural systems in terms of anthropogenic load // Russian scientific world. 1, 2013

2. KOVDA V.A. The issue of desertification and salinization in arid regions of the world - V.A. Kovda; [chief.edit. Pankov E.I., Aydarov I.P.]; Institute of Physics-chemical and biol. issues of Soil Science;Nauka: Moscow, 51, 2008.

3. UNEP. World Atlas of Desertification. EdwardArnold: London, 1992.

4. PANKOVAE. I., KONYUSHKOVA M.V. Climate and Soil Salinity in the Deserts of Central Asia. Eurasian Journal of Soil Science, 46, 7, 2013.

5. DEVKOTA M., MARTIUS C., GUPTA R.K., DEVKOTA K.P., MCDONALD A.J., LAMERS J.P.A. Managing soil salinity with permanent bed planting in irrigated production systems in Central Asia. Agriculture, Ecosystems and Environment, 202, 1, 2015.

6. BOROVSKY V.M. Formation of saline soils and galogeochemical areas of Kazakhstan. Publishing house "Science" Kazakh SSR: Almaty, 256, 1982.

7. OTAROV A., IBRAYEVA M.A, USIPBEKOV M., WILKOMIRSKI B., SUSKA-MALAWSKA M. Brief description of soil surface and analysis of current state of soil fertility in South Kazakhstan region. Journal Soil Science and Agrichemistry, 1, 1, 2008.

8. KOSHAL A.K. Spectral Characteristics of Soil Salinity Areas in Parts of South-West Punjab through Remote Sensing and GIS. International Journal of Remote Sensing and GIS, 1, 2, 2012.

9. JABBAR M.T., CHEN X. Land Degradation Due to Salinization in Arid and Semi-Arid Regions with the Aid of Geo-Information Techniques. Geo-Spatial Information Science, 11, 2, 2008

10. LHISSOU R., HARTI E.A., CHOKMANI K. Mapping soil salinity in irrigated land using optical remote sensing data. Eurasian Journal of Soil Science 3, 2014

11. ABBAS A., KHAN S., HUSSAIN N., HANJRA M.A., AKBAR, S. Characterizing soil salinity in irrigated agriculture using a remote sensing approach. Physics and Chemistry of Earth, Parts A/B/C, 55-57, 2013.

12. JINGWEI W., VINCENT B., YANG J., BOUARFA S., VIDAL A. Soil Salinity Mapping and Monitoring in Arid and Semi-Arid Regions Using Remote Sensing Technology: A Review. Advances in Remote Sensing, 2, 2013.

13. METTERNICHT G., ZINCK A., Remote Sensing of Soil Salinization: Impact on Land Management, CRC Press, 2008.

14. ELDEIRY A.A., GARCIA L.A. Detecting soil salinity in alfalfa fields using spatial modeling and remote sensing. Soil Water Management and Conservation, 72, 1, 2008.

15. IQBAL F. Detection of salt affected soil in rice-wheat area using satellite image. African Journal of Agricultural Research, 6 (21), 2011.

16. WIEGAND C.L., RHOADES J.D., ESCOBAR D.E., EVENITT J.H. Photographic and videographic observations for determining and mapping the response of cotton to soil salinity. Remote Sensing of Environment, 49 (3), 1994.

17. SAVIN I.Y., OTAROV A., ZHOGOLEV A.V., IBRAYEVA M.A., DUISEKOV S. Determination of long-term changes of saline soils area in irrigated areas in Shaulder based on space imagery Landsat. Bulletin of Soil Science Institute V.V. Dokuchaev, 74, 2014.

18. DARVISHSEFAT A.A., DAMAVANDI M.H., JAFARI M., ZEHTABIYAN G.R. Assessing of Landsat TM images for using in soil salinity classification. Journal of Desert, 5, 2, 2000.

19. GOOSSENS R., ALAVIPANAH S.K., DE DAPPER M., KISSIYAR O. The use of thermal band of Landsat TM for the study of soil salinity in Iran (Ardakan area) and Egypt (Ismailia Province). In: Proceedings International Conference on Geoinformatics for Natural Resource Assessment, Monitoring and Management. Indian Institute of Remote Sensing, NRSA: Dehradun (India), 454, 1999.

20. ALAVIPANAH S. K., GOOSSENS R., MATINFAR H. R., MOHAMADI H.,GHADIRI M., IRANNEGAD H., ALIKHAHASI M. The Efficiency of Landsat TM and ETM+ Thermal Data forExtracting Soil Information in Arid Regions. J. Agric. Sci. Technol., 10, 2008.

21. SANAEINEJAD S.H., ASTAREI A.P., MIRHOSEINI M., GHAEMI M. Selection of band combination for soil salinity studies using ETM+ satellite images (A case study: Nyshaboor Region, Iran). World Academy of Science, ENGINEERING AND TECHNOLOGY, 30, 2009.

22. METTERNICHT G.I. Fuzzy classification of JERS-1 SAR data: an evaluation of its performance for soil salinity mapping. Ecological Modelling, 111 (1), 1998.

23. ALLBED A., KUMAR L., ALDAKHEEL Y. Assessing soil salinity using soil salinity and vegetation indices derived from IKONOS high-spatial resolution imageries: Applications in a date palm dominated region.Geoderma, 230-231, 2014.

24. SAID N., HENNING B., JOACHIM H. Digital Mapping of Soil Properties Using Multivariate Statistical Analysis and ASTER Data in an Arid Region. Remote Sens. 7, 2015.

25. LOBELL D., LESCH S.M., CORWIN D.L., ULMER M.G., ANDERSON K.A., POTTS D.J., DOOLITTLE J.A., MATOS M.R., BALTES M.J. Regional-Scale Assessment of Soil Salinity in the Red River Valley Using Multi-Year MODIS EVI and NDVI. Journal of Environmental Quality, 39, $1,2010$.

26. MAMUTOV ZH.U., LAISKHANOV SH.U. Increasing of efficiency of natural vegetation inOtrar district of South Kazakhstan region. "Al-Farabialemi": proceedings of international conference of students and young scientists. Publishing House of KazNU: Almaty, 11, 2014.

27. Encyclopedia: “Otyrar". Arys: Almaty, 298, 2005.

28. ZHIKHAREVA G.A., KURMANGALIYEV A.B., SOKOLOV S.S. The soils of Kazakh SSR:Shymkent area. Issue 12; Publishing house "Science" Kazakh SSR: Alma-Ata, 410, 1969.

29. CSILLAG F., PASZTOR L., BIEHL L. Spectral band selection for the characterization of salinity status of soils. Remote Sensing of environment, 43, 1993.

30. DARWISH KH.M., KOTB M.M., ALI R. Mapping soil salinity using collocated cokriging in Bahariya Oasis, Egypt. Spatial Data Quality: Proc. of the 5th Intern. Symp., 13 June - 15 June 2007. Intern. Institute for geo-Information Science and Earth Observation.

31. PENG W. Synthetic analysis for extracting information on soil salinity using remote sensing and GIS: A case study of Yanggao basin in China. Environmental Management, 22 (1), 1998.

32. SHRESTHA D.P., FARSHAD A. Mapping salinity hazard: an integrated application of remote sensing and modelingbased techniques. In: Remote sensing of soil salinization. Impact on land management, 257, 2009.

33. WENG Y., GONG P., ZU Z. Soil salt content estimation in the Yellow River delta with satellite hyperspectral data. Can. J. Remote Sensing, 34, 3, 2008.

34. A. CHEREPANOV Vegetation index. Geomatics, 2, 2011. 
35. All-union guideline on soil surveys and large-scale soil maps of land use. Kolos: Moscow, 95, 1973.

36. Guidelines for large-scale soil survey in the Kazakh SSR. Alma-Ata, 137, 1979.
37. CHERNYSHEV A.K. Measuring the concentration of salts "Progress-1T" (brief description, method of calibration, manual and measurement). Tashkent, 47, 2006. 